\title{
Minimal change in children's lifestyle behaviours and adiposity following a home-based obesity intervention: results from a pilot study
}

\author{
Nicola J. Spurrier ${ }^{1,2,3}$, Lucinda Bell ${ }^{4}$, Annabelle Wilson ${ }^{5}$, Elizabeth Lowe ${ }^{6}$, Rebecca Golley ${ }^{7 *}$ \\ and Anthea A. Magarey ${ }^{4}$
}

\begin{abstract}
Background/Methods: Families of overweight and obese children require support to make sustainable lifestyle changes to improve their child's diet and activity behaviours and in turn weight status. The aim of this pre-post intervention pilot study was to evaluate the feasibility of an individualised home-based intervention for treatment seeking overweight/obese 4-12 year olds and their caregivers. Baseline measures were used to develop a family-specific intervention to improve the quality of the home environment. The intervention was delivered as individualised written recommendations and resources plus phone call and home visit support. Baseline measures were repeated approximately 6 months later.
\end{abstract}

Results: Complete data for 24 children was available. Parents reported that $43 \%$ of intervention recommendations were implemented 'very much'. Some descriptive changes were observed in the home environment, most commonly including fruit and vegetables in their child's lunchbox, not providing food treats, and restricting children's access to chips/savoury snack biscuits. At the group level, minimal change was detected in children's diet and activity behaviours or weight status (all $p>0.05$ ).

Conclusion: The study findings did not support intervention feasibility in its current form. Future interventions should target the family food and activity environment, but also utilise an approach to address the complex social circumstances which limit parent's ability to prioritise healthy family lifestyle behaviours.

Trial registration: Australian New Zealand Clinical Trials Registry (ANZCTR) 3/12/2014. http://www.ANZCTR.org.au. ACTRN12614001264673

Keywords: Child, Obesity, Treatment, Home environment, Diet, Family

\section{Background}

Childhood obesity is recognised as one of the most significant public health problems in developed countries. Families of overweight children need services and support to make sustainable lifestyle changes to improve

\footnotetext{
*Correspondence: Rebecca.golley@unisa.edu.au

${ }^{7}$ Sansom Institute for Health Research, University of South Australia,

Adelaide 5001, Australia

Full list of author information is available at the end of the article
}

their child's diet and activity behaviours and in turn weight status $[1,2]$.

The obesity epidemic is largely considered to be due to increased availability of energy-dense foods and reduced opportunities for physical activity, characteristics of a modern society [3, 4]. Obesity-promoting environments have been described in terms of macro- and micro- environments [4]. The family home is an important microenvironment with the potential to influence children's lifestyle behaviours and weight status [5]. Observational studies have identified modifiable characteristics of 
children's home food and activity environments that are associated with diet quality and activity levels [6-10]. For example, we have previously characterised the home environment of 208 preschool children [11]. Parental role-modelling of physical activity, a safe and engaging backyard, having rules for use of small screen entertainment, using appropriate child feeding behaviours, and stocking more healthy food and less energy-dense nutrient poor foods in the home were associated with greater physical activity levels, less sedentary behaviour and healthier dietary patterns [11].

Child weight management that is based on practical advice on how to create a supportive home environment may be more effective than prescribing strict dietary or physical activity regimens, particularly if changes can become incorporated into a daily routine and sustained long term $[12,13]$. Strategies to improve the home environment are often provided as part of weight management advice in clinic settings. However it can be difficult for families to translate this advice into reality. Working with parents in their homes is a potential alternative intervention setting which may make it easier for health care providers to assess areas for change and better appreciate family barriers. Home visits may also facilitate development of supportive therapeutic relationships. Home visiting has been trialled in obesity prevention studies with young children [14], but to date this approach has not been used in obesity treatment interventions for children who are already overweight or obese.

The home has been shown to be a successful intervention setting in other health areas, the best example being home visiting by nurses or other trained health visitors to support mothers living in disadvantage during the early years of child rearing [15]. Other examples in paediatrics include chronic diseases such as asthma [16, 17]. Some of the postulated reasons for the success of such programs include the increased ability for health visitors to build successful therapeutic relationships with family members and the fact that health visitors can more fully appreciate the socioeconomic and cultural environment in which families operate.

The aim of the current pilot intervention study was to assess the feasibility of an individualised home-based intervention for children with obesity whose parents were seeking treatment. Outcomes assessed included changes to the home environment and improvements in children's dietary and physical activity behaviours and weight status.

\section{Methods}

\section{Study design and recruitment}

A pre-post design evaluated a home-based lifestyle support intervention conducted in 2008. It was hypothesized that an individualised home-based intervention would be a feasible child obesity treatment approach. Children aged 4-12 years who were overweight or obese according to the International Obesity Task Force (IOTF) Body Mass Index (BMI) cut-points [18] and who were living in metropolitan Adelaide were recruited via referrals to the Department of Paediatrics and Child Health, Flinders Medical Centre for management of obesity. Exclusion criteria were medical conditions affecting weight or growth or being enrolled in any other structured weight management program, however no child was excluded on these grounds. Children could continue to be managed by their general practitioner or paediatrician during the intervention. Written informed parent consent and child assent was obtained. The study was approved by the Flinders University Social and Behavioural Research Ethics committee.

The study sequence is shown in Fig. 1. At baseline and follow up, participants attended a 1-h assessment at which anthropometry and questionnaire data were obtained. This was followed by a 75-min home visit to assess the home environment. The three home visitors were trained via a $3 \mathrm{~h}$ workshop covering the socioecological basis of childhood obesity, dietary and physical activity guidelines, and how to work with families in non-judgemental partnerships. Comprehensive written instructions and a training site visit ensured a standardised procedure was followed.

\section{Measures}

At baseline a socio-demographic questionnaire was completed by parents, and child weight, height and waist circumference were measured to the nearest $0.1 \mathrm{~kg}$ and $0.1 \mathrm{~cm}$, using standardised scales and stadiometer. These measurements were undertaken in the paediatric outpatient department, Flinders Medical Centre, using the same set of scales and stadiometer for each child and at both baseline and follow-up. The research assistant undertaking these measurements was not involved in the home visit intervention and had been trained in anthropometry. Specifically, children were weighed on portable digital scales wearing light clothing, with shoes and socks removed. Height was measured using a wall-mounted stadiometer with shoes and socks removed, heels touching the wall and head in the 'Frankfort' plane. Waist circumference was measured using a standard metric tape measure held horizontally at a level midway between the lower rib margin and iliac crest (approximately in line with the umbilicus). BMI was calculated (weight, $\mathrm{kg} /$ height, $\mathrm{m}^{2}$ ) and weight status determined by applying the IOTF cutpoints [18]. BMI and waist circumference $\mathrm{z}$-scores were calculated using LMSGrowth Excel add-in which is based on 1990 United Kingdom reference data [19, 20]. 


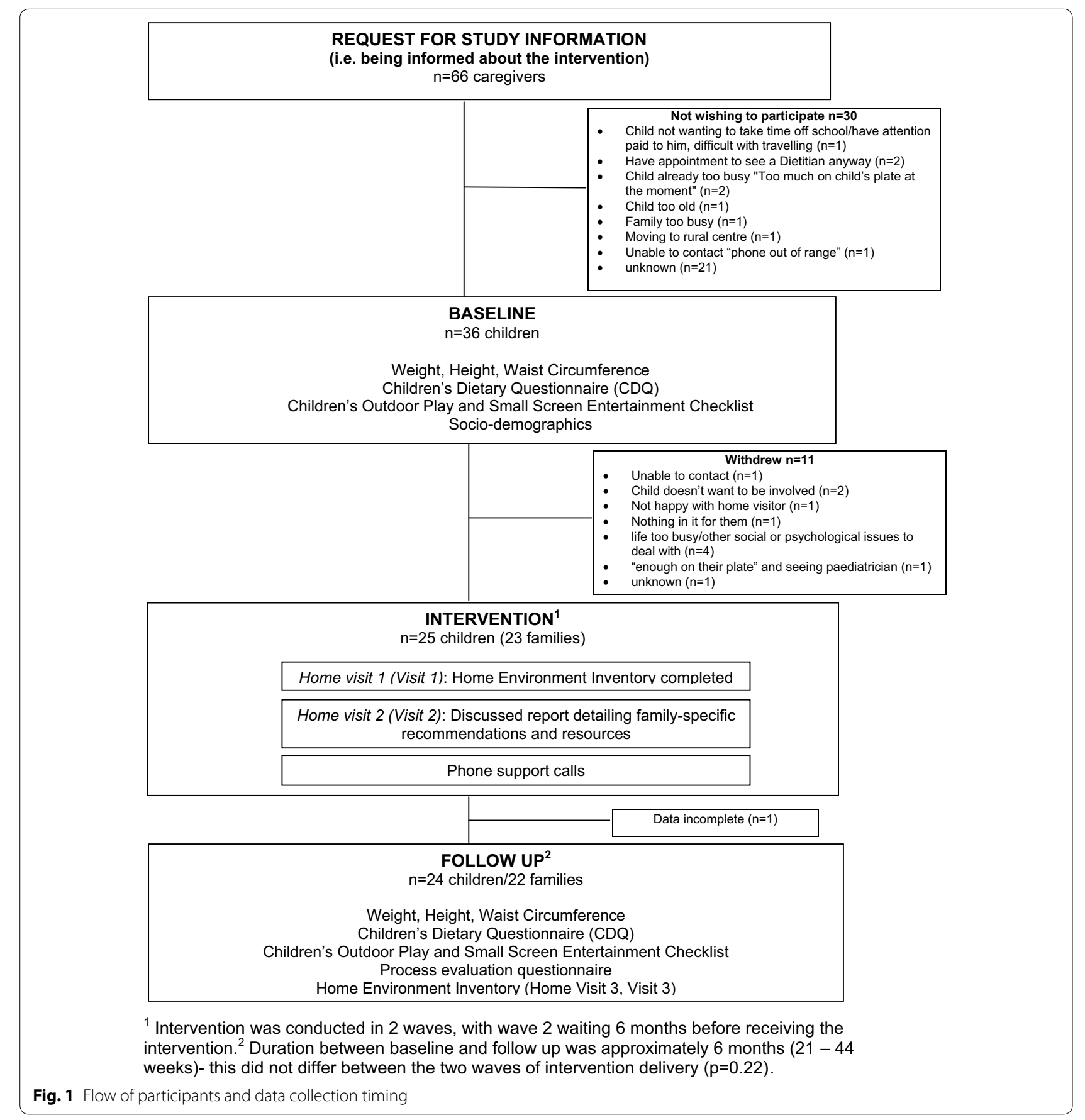

Parents completed the 24-item Children's Dietary Questionnaire (CDQ) [21] which generates four continuous scores (i.e. fruit and vegetables, non-core foods, fat from dairy, sweetened beverages). Non-core foods are defined as foods that are not essential to meet nutrient requirements and contain excess energy, fat, sugar and salt [22]. The CDQ shows acceptable reliability (ICC $0.5-0.9)$ and relative validity at the group level for the fruit and vegetables and non-core food scores (Cronbach alpha 0.62-0.72) [21].

Child activity patterns were measured using an adapted version of The Outdoor Play and Small Screen Entertainment Checklist [11, 23]. Parents reported the average time children spent per weekday and weekend day (in hours and minutes) (1) playing outdoors, (2) doing moderate-vigorous physical activity, and (3) using electronic 
media such as television and computers for both. Six items were added to the original checklist to explore average time spent per day (4) participating in physical activity and (5) using small screen entertainment. Times were averaged (weighted for type of day) to calculate (1) daily activity (vigorous physical activity + outdoor play) and (2) daily sedentary activity.

The Home Environment Inventory provides an assessment of 70+ family home characteristics associated with children's dietary, physical activity, or sedentary behaviours [11]. Items cover the outdoor environment to support children's play, parental role modelling, accessibility of small screen entertainment, parent behaviours around food preparation and availability of healthy and non-core foods and beverages in the home and child's lunchbox. Inventory items were assessed by either direct observation or by parental report (details described elsewhere [11]).

\section{Study intervention}

The study intervention was based on ecological theory $[3,24,25]$. The intervention was undertaken in family's homes by trained visitors. Three home visits and two follow-up phone calls were offered to each family. Three home visitors were trained in the methodology with particular emphasis on being nonjudgmental, supportive and sensitive to socioeconomic determinants of obesity. Home visitors were chosen for their interpersonal skills and in this study all three were in the process of completing bachelor degrees in either nutrition, occupational therapy or human movement. The family was contacted by telephone by the home visitor who introduced themselves, explained the process and made a suitable time for the first home visit (Visit 1). At Visit 1 the home visitor clarified that the carer (in all instances this was the mother) understood the study and evaluated the family's home environment using the Home Environment Inventory. The completed Home Environment Inventory was used to identify changes the family needed to make to improve the home environment. These changes were set as the intervention goals. To provide advice for each family, these goals were used to individualise a report template containing 25 strategies, along with ideas of how each strategy could be implemented. The ten most relevant strategies for each family were highlighted at the beginning of the report. This report was presented to the family at a second home visit (Visit 2), conducted approximately 2 weeks ( \pm 1 week) after Visit 1 . The purpose of Visit 2 was to go through the report with the parent and to discuss ways of achieving change that the parent felt would be manageable for their family situation. The strategies were based on key evidence for improving healthy eating and physical activity in children [5, 22, 25-28].
Any additional issues relevant to achieving the desired outcomes that mother/family/carer identified during the home visit were noted for example housing, budgeting and child behaviour. The impact of these socioeconomic factors on the ability of families to institute change became more obvious once the study progressed and by the fact that visits were undertaken in the family home. The importance of this aspect of obesity management is illustrated in the case study provided in Fig. 2.

At Visit 2, time was made for the first follow-up phone call approximately 1 month after Visit 2 . The purpose of this phone call was to gauge the family's progress, provide ongoing support and encouragement with regards to the strategies and to provide further advice and support if requested. If families requested additional information, standard resources were posted to them (for example label reading) or a suggestion was provided about where they could access assistance (for example a child psychologist). The phone calls also provided opportunity to discuss any strategies that families felt were not working, and make alternative suggestions. At the end of the call, a time was made for the second follow-up phone call which was to occur approximately a month after the first phone call. And at the end of this call, a time for the final home visit (Visit 3) was made (aiming to be approximately 4 months after Visit 1). At Visit 3, the inventory was repeated. Encouragement for continuing to make lifestyle changes was also given to the families at this final visit.

\section{Statistical analysis}

Analyses were conducted using SPSS for Windows version 17.0. Descriptive statistics are presented as frequencies or mean (standard deviation)/median (IQ range). Wilcoxin signed-rank tests and paired $t$ tests were used to assess changes from baseline to follow up in subscale scores for the CDQ, Physical Activity Questionnaire and anthropometric data. Categorical data from the Home Environment Inventory were analysed using Chi square tests for independence. Statistical significance was set at $\mathrm{p}<0.05$.

\section{Results}

\section{Sample characteristics}

Figure 1 summarises the flow of participants through the study (duration approximately 6 months, 21-44 weeks). Complete follow-up data was available for 24 children (14 boys; $25 \%$ overweight and $75 \%$ obese). Demographic characteristics of study families are shown in Table 1.

\section{Home environment characteristics}

Table 2 shows the most frequent recommendations made to families in the intervention phase. Forty-three percent of recommendations were implemented 'very much' 


\section{Context}

- Brett, a nine year old boy and Valerie, a single mother

- Brett lived with both his mother and father at different times

Issues identified by home visitor

- All family members overweight

- Valerie very motivated for the family to change

- Difficult to engage family in discussions about food and activity, despite high motivation

- Home visit provided an opportunity for Valerie to 'debrief' about multiple issues

- Home visit provided an increased awareness of home environmental barriers such as cramped public rental accommodation, small backyard with long grass and dog litter

Issues identified by Valerie

- Brett's behavioural issues - difficulty concentrating at school and behaviour management a problem

- Inadequate housing - frequently moved around and lack of stability

- Different dietary messages being conveyed by mother and father which confused Brett

Home visitor actions

- Listened to Valerie's concerns about Brett's behavioural issues and suggested consulting a child psychologist

- When asked, provided a letter of support to the state housing department for Valerie to receive a stable place of residence

- Broached dietary and physical activity issues when appropriate (i.e. when other issues less of a concern)

Home visitor learnings

- Home visitor more aware of family's situation from visiting Brett and Valerie's home

- Diet and physical activity will not always be the family's immediate priority

\section{Outcomes}

- Home visitor process took longer than first anticipated

- Home visits put on hold while family received a stable place of residence and recommenced after this was achieved

Fig. 2 Intervention case study—Brett and Valerie

(Table 2). Baseline and follow up family environment characteristics as measured at the home visit are shown in Table 3. Recommendations to include fruit and vegetables in their child's lunchbox, not providing food treats, and restricting access to chips/savoury snack biscuits (in the home and lunchbox), appeared to be implemented more easily than other recommendations. Parents being active every day, children spending time outside, family members not eating in front of the television and restricting the availability of certain non-core foods in the home appeared more difficult to implement.

\section{Children's lifestyle and anthropometry}

Baseline and follow up lifestyle behaviours and anthropometry are shown in Table 4. Score improvements occurred in about half the sample for fruit and vegetables $(\mathrm{n}=12)$, sweetened beverages $(\mathrm{n}=14)$, non-core food $(\mathrm{n}=12)$, outdoor playtime $(\mathrm{n}=14)$, sedentary 
Table 1 Demographic characteristics of study participants at baseline

\begin{tabular}{ll}
\hline Characteristic & N (\%) or mean (SD) \\
\hline Child's age (years) $n=24$ & $7.8( \pm 2.3)$ \\
Child's gender $n=24$ & Male:Female 14:10 \\
Household structure $(n=22)$ & \\
Two parent household & $15(68.2)$ \\
Single parent household & $7(31.8)$ \\
Mother's education level $(n=21)$ & \\
Some years of high school & $2(9.5)$ \\
Year 12, HSC or equivalent & $5(23.8)$ \\
Technical, trade, or TAFE certificate & $5(23.8)$ \\
Tertiary qualifications & $9(42.9)$ \\
Father's education level $(n=22)$ & \\
Some years of high school & $5(22.7)$ \\
Year 12, HSC or equivalent & $4(18.2)$ \\
Technical, trade, or TAFE certificate & $5(22.7)$ \\
Tertiary qualifications & $8(36.4)$ \\
Mother in paid employment $(n=21)$ & \\
Yes & $17(81.0)$ \\
Father in paid employment $(n=22)$ & \\
Yes & $20(90.9)$ \\
Household income (per week) $(n=17)$ & $2(11.8)$ \\
$<\$ 500$ & $3(17.6)$ \\
$<\$ 500-\$ 999$ & $3(17.6)$ \\
$\$ 1000-\$ 1499$ & $4(23.5)$ \\
$\$ 1500-\$ 1999$ & $5(29.4)$ \\
$\geq \$ 2000$ & \\
\hline
\end{tabular}

time $(\mathrm{n}=11)$ and time spent in daily activity $(\mathrm{n}=13)$. Around one-third demonstrated improvements in time spent in sedentary activity $(\mathrm{n}=9)$. One child shifted from "overweight" into the "healthy weight" range, all others remained in the same weight category. Improvements in BMI z scores were recorded for $15 / 24$ children; 10 decreasing by $\geq 5 \%$ and 5 decreasing by $\leq 5 \%$. Improvements in waist circumference $\mathrm{z}$ scores were recorded for 18 children; 12 decreasing by $\geq 5 \%$ and 6 decreasing by $\leq 5 \%$. On the other hand, BMIz score increased by $>5 \%$ in $3 / 24$ children and Waist Circumference $z$ scores increased by $>5 \%$ in $3 / 24$ children.

\section{Discussion}

This pilot study explored the feasibility of a home-based child weight management intervention. Families from a range of different socioeconomic backgrounds participated in the study. The intervention involved direct assessment of the family food and activity environment which informed individualised recommendations for family change. It was hypothesised that improving the family food and activity environment would lead to improvements in children's dietary and physical activity behaviours, and thus weight status. While the study findings support the family environment as a target for intervention, provision of simple individualised recommendations appeared to be insufficient to enable families to significantly alter their home food and activity environment.

Baseline findings demonstrated the potential for improvement in the home environments of this sample of overweight and obese children. For example, while it was common for families to eat together, so was eating meals in front of the television. Likewise, while healthy foods such as fruit and vegetables were available in homes, so were large amounts of energy dense, nutrient poor foods. In terms of physical activity, role modelling of television viewing was more common than modelling of activity and in general there were limited opportunities for active play.

The most frequent intervention recommendations made to families targeted parental role modelling of physical activity, encouragement of outdoor active play, reducing children's exposure to energy dense nutrient poor foods and increasing availability of fruit and vegetables in lunchboxes. Post-intervention, small positive changes in the home environment were observed. Most related to children's access to food in the home and lunchbox; greater access to vegetables and restriction of high fat/high salt non-core foods and food 'treats'. Recommendations which appeared difficult for parents to implement were purchasing take-away food, eating food in front of the TV, having large amounts of non-core food in the home, and taking children to playgrounds or parks. Whilst some individual change occurred in lifestyle behaviours, at the group level few changes were detected in children's diet and activity patterns. While BMI and Waist Circumference $\mathrm{z}$ scores improved for approximately two-thirds of children, at the group level the changes were small relative to the effects observed in other child weight management intervention studies [12] even accounting for the small sample size.

A home visit approach enables direct assessment of the home environment so that families can receive tailored advice about changes to improve children's diet, activity patterns and weight status. However in this pilot study, families either did not achieve the necessary change or the degree of change was not sufficient to detect improvements in children's diet and activity behaviours or weight status. The lack of intervention effect may reflect the need for more intensive and ongoing support particularly with respect to competing demands on family time and resources. Multidisciplinary expertise is often needed to appreciate and confront the complex psychosocial and environmental constraints families are challenged with, 
Table 2 Common intervention recommendations and caregiver-reported success in implementing change at home ( $n=22$ families)

\begin{tabular}{|c|c|c|c|c|c|}
\hline \multirow[t]{2}{*}{ Recommendation } & \multirow{2}{*}{$\begin{array}{l}\text { Number of families } \\
\text { given this recommendation }\end{array}$} & \multicolumn{4}{|c|}{ How well were changes implemented? (self-reported) } \\
\hline & & Very much & Some-what & A little & Not at all \\
\hline $\begin{array}{l}\text { Encourage all household members to spend some } \\
\text { active time outside each day }\end{array}$ & 21 & 9 & 7 & 5 & 0 \\
\hline Spend time outside with your child daily & 19 & 8 & 5 & 5 & 1 \\
\hline $\begin{array}{l}\text { Restrict availability of non-core foods (e.g. savoury } \\
\text { snacks, cake) }\end{array}$ & 16 & 8 & 7 & 1 & 0 \\
\hline $\begin{array}{l}\text { Include fruit and vegetables in your child's lunch box } \\
\text { every day }\end{array}$ & 15 & 11 & 3 & 0 & 1 \\
\hline Reduce portion sizes & 12 & 5 & 6 & 1 & 0 \\
\hline Avoid family members eating in front of TV & 9 & 3 & 3 & 1 & 2 \\
\hline Limit takeaway food to 1-2 times per month & 9 & 5 & 4 & 0 & 0 \\
\hline Restrict sweetened beverages (including fruit-juice) & 8 & 4 & 4 & 0 & 0 \\
\hline Try new strategies to avoid wasting food & 8 & 5 & 2 & 1 & 0 \\
\hline Avoid having the TV on during mealtimes & 7 & 3 & 0 & 1 & 3 \\
\hline $\begin{array}{l}\text { Avoid putting non-core snack foods in your child's } \\
\text { lunch box (including muesli/health/breakfast bars) }\end{array}$ & 7 & 2 & 4 & 1 & 0 \\
\hline
\end{tabular}

TV television

particularly those living in disadvantage. By this we mean that the skill-set of the team needs to include provision of support for social and emotional issues of both the child and family when necessary. Whilst our home visitors attempted to provide some of this support, it was not the focus of this intervention.

In addition, only the top ten environmental factors were targeted for each family. It may well be that these initial suggestions were just the first step in change and that subsequent visits were needed to focus on other aspects of the home environment to allow a greater intervention effect. Finally, it should be noted that only $36 / 66$ (55 \%) caregivers who sought information about this study, agreed to enrol their child. Whilst we had considered home visits to be more convenient for parents, parental anxiety around possible negative judgement about their home and household circumstances may well have contributed to this poor recruitment response.

Trials of home based intervention in other areas of health have had variable success. Segal et al. undertook an extensive review of home visiting for prevention of child maltreatment [29]. They demonstrated that those trials clearly grounded in a theory or mechanism of change and with an intervention most consistently based on this theory were successful. On the other hand, trials where no underlying theory was described were not successful. A positive feature of our current study was that we based the intervention on ecological theory; that is we sought to change the home environments of children with obesity $[3,24]$. However, one of the reasons that our intervention may have had limited success, is that ecological theory regarding obesity development suggests that macro-environments exert greater influence on obesity development/maintenance than parent's ability to optimise the family home environment [30].

In the area of childhood asthma, Brown et al. discussed other possible reasons for the limited benefit observed following regular nurse home visits compared to standard clinic care [31]. Nurses cited poor time management, personal problems or the family's living environment as the greatest barriers to program success for about $40 \%$ of families. As our study progressed, the complex and sometimes chaotic social issues faced by many families became more obvious and these took priority for families over positive lifestyle change. Brown et al. also reported that nurses who were more judgemental and less flexible were least successful in terms of taking families through completion of the asthma education program [31]. In contrast, the home visitors in our study had been chosen because of their interpersonal style and we had specifically addressed the issue of obesity stigmatisation and importance of not being judgemental in our pre-intervention training.

The findings of this study must be interpreted in the context of its strengths and limitations. This is one of few studies to measure elements of the home environment by direct observation instead of parental report. The study included both assessments of dietary and physical activity patterns rather than focusing on only one side of the energy balance equation. However, as with any self-report methodologies these data could be at risk 
Table 3 Frequency (percentage) of selected home environment inventory variables pre- and post-intervention $(\mathbf{n}=\mathbf{2 2}$ )

\begin{tabular}{|c|c|c|c|c|}
\hline Variable & & Response category & Baseline & Follow up \\
\hline \multicolumn{5}{|l|}{ Parental role modelling of physical activity } \\
\hline \multirow[t]{2}{*}{ How often } & Mother walks for $\geq 30$ min & Once/month or more & $18(82)$ & $15(68)$ \\
\hline & Father walks for $\geq 30 \mathrm{~min}$ & Once/month or more & $14(67)$ & $18(82)$ \\
\hline \multirow[t]{2}{*}{ How many } & Hours of TV mother watches/day & $>2 \mathrm{~h}$ & $5(26)$ & $6(30)$ \\
\hline & Hours of TV father watches/day & $>2 \mathrm{~h}$ & $14(70)$ & $9(47)$ \\
\hline \multicolumn{5}{|l|}{ Opportunities for outdoor play } \\
\hline \multirow[t]{2}{*}{ How often } & Child taken to the playground & $\geq$ Twice/week & $3(14)$ & $4(18)$ \\
\hline & Child taken to the park & $\geq$ Twice/week & $2(9)$ & $2(9)$ \\
\hline \multicolumn{5}{|l|}{ Family norms } \\
\hline \multirow[t]{4}{*}{ How often } & Child eats evening meal in front of TV & Frequently/sometimes & $10(45)$ & $10(48)$ \\
\hline & Other family members eat food in front TV & Frequently/sometimes & $10(45)$ & $10(45)$ \\
\hline & Adults set rules for child's TV viewing & Very much/quite a bit & $12(57)$ & $15(75)$ \\
\hline & Adults limit child's exposure to TV advertising & Very much/quite a bit & $6(27)$ & $8(38)$ \\
\hline \multicolumn{5}{|l|}{ Food accessibility } \\
\hline \multirow[t]{3}{*}{ How often adults restrict child access to } & Fruit juice & Frequently/Sometimes & $16(73)$ & $16(73)$ \\
\hline & High fat/high sugar foods & Frequently/Sometimes & $22(100)$ & $21(95)$ \\
\hline & Soft drink/cordial & Frequently/Sometimes & $18(82)$ & $18(82)$ \\
\hline How often & Adults give child food 'treats' & Frequently/Sometimes & $9(41)$ & $5(23)$ \\
\hline What is & Portion size of child's main meal & $>1 / 2$ average dinner plate & $9(41)$ & $7(32)$ \\
\hline How family & Feels about wasted food & Very accepting/accepting & $10(45)$ & $12(54)$ \\
\hline \multicolumn{5}{|l|}{ Availability of food in the home } \\
\hline \multirow[t]{9}{*}{ Amount of } & Fruit & $>3 \mathrm{~kg}$ & $15(68)$ & $16(73)$ \\
\hline & Vegetables & $>6 \mathrm{~kg}$ & $13(59)$ & $12(55)$ \\
\hline & Fruit juice & $>2 \mathrm{~L}$ & $5(23)$ & $7(32)$ \\
\hline & Dairy & All reduced fat & $16(73)$ & $18(82)$ \\
\hline & Chips/savoury snack biscuits & $>100 \mathrm{~g}$ & $17(77)$ & $5(68)$ \\
\hline & Lollies/sweets/chocolate & $>120 \mathrm{~g}$ & $12(55)$ & $13(59)$ \\
\hline & Muesli/chocolate bars & $>0.5$ boxes & $14(64)$ & $13(59)$ \\
\hline & Cakes/biscuits & $>140 \mathrm{~g}$ & $12(55)$ & $11(50)$ \\
\hline & Soft drink/cordial & $>2 \mathrm{~L}$ & $18(82)$ & $15(68)$ \\
\hline \multicolumn{5}{|l|}{ Availability of food in the child's lunchbox } \\
\hline \multirow[t]{6}{*}{ How often lunchbox contains } & Fruit & Frequently/sometimes & $20(91)$ & $21(95)$ \\
\hline & Vegetables & Frequently/sometimes & $7(32)$ & $13(59)$ \\
\hline & Chips/savoury snack biscuits & Frequently/sometimes & $12(54)$ & $7(32)$ \\
\hline & Lollies/sweets/chocolate & Frequently/sometimes & $1(5)$ & $1(5)$ \\
\hline & Muesli/breakfast bars & Frequently/sometimes & $7(32)$ & $7(32)$ \\
\hline & Cakes/biscuits & Frequently/sometimes & $7(32)$ & $7(32)$ \\
\hline
\end{tabular}

Variables presented reflect the most common areas for concern for families in the intervention

TV television

of measurement and social desirability bias. Practical aspects of ensuring a healthy lifestyle for children by parents were examined resulting in data that has real utility for health professionals dealing with overweight children and their families. However the sample size of this pilot study was small. Results should be viewed with caution and be useful primarily to inform future intervention studies rather than clinical practice.

\section{Conclusion}

In conclusion, this home-based intervention pilot study in which families of overweight and obese children were advised to change aspects of their home environment was not effective in improving children's dietary and physical activity behaviours, or weight status. Future child obesity interventions should target factors which families struggle to change, provide additional behaviour 
Table 4 Children's anthropometry, dietary and activity scores pre- and post-intervention $(n=24)$

\begin{tabular}{lccc}
\hline & Baseline & Follow-up & P value \\
\hline Anthropometric characteristics & & & \\
Height $(\mathrm{cm})$ & $135.2 \pm 14.3$ & $138.7 \pm 13.8$ & \\
Weight $(\mathrm{kg})$ & $45.7 \pm 13.8$ & $48.6 \pm 13.0$ & 0.46 \\
BMI (kg/m $\left.{ }^{2}\right)$ & $24.5 \pm 3.2$ & $24.8 \pm 3.1$ & 0.77 \\
BMI z score & $2.9 \pm 0.7$ & $2.8 \pm 0.7$ & 0.69 \\
Waist circumference $(\mathrm{cm})$ & $77.8 \pm 9.7$ & $77.7 \pm 8.7$ & 0.97 \\
Waist circumference Z score & $3.2 \pm 0.6$ & $3.0 \pm 0.5$ & 0.22 \\
CDQ scores & & & \\
Fruit and vegetables & $11.4 \pm 4.4$ & $10.9 \pm 4.1$ & 0.60 \\
Fat from dairy & $0.9 \pm 0.9$ & $1.0 \pm 1.2$ & 0.73 \\
Sweetened Beverages & $1.4 \pm 1.1$ & $1.3 \pm 1.0$ & 0.38 \\
Non-core foods & $2.0 \pm 0.8$ & $1.7 \pm 0.6$ & 0.79 \\
Activity scores & & & \\
Outdoor playtime & $6.7 \pm 3.5$ & $6.8 \pm 3.3$ & 0.56 \\
Sedentary time & $2.9 \pm 1.9$ & $2.7 \pm 1.4$ & 0.60 \\
Minutes daily activity & $163 \pm 61$ & $174 \pm 109$ & 0.93 \\
Minutes sedentary activity & $140 \pm 74$ & $132 \pm 69$ & 0.59 \\
\hline
\end{tabular}

Duration between baseline (pre-intervention) and follow up (post-intervention) $\sim 6$ months

modification support, and utilise a multi-disciplinary approach to address the complex social circumstances which limit parents' ability to prioritise healthy family lifestyle behaviours.

\section{Authors' contributions}

NS, RG, AM conceived and designed the study. LL, AW were responsible for data collection. NS, LB analysed the data. All authors were involved in interpreting the data and drafting or revising the manuscript. All authors read and approved the final manuscript.

\section{Author details}

${ }^{1}$ Department of Public Health, University of Adelaide, Adelaide 5000, Australia. 2 Department of Paediatrics and Child Health, Flinders University, Bedford Park 5042, Australia. ${ }^{3}$ Department for Health and Ageing, SA Health, Citi Centre Building, 11 Hindmarsh Square, Adelaide, SA 5000, Australia. ${ }^{4}$ Nutrition and Dietetics, Flinders University, Bedford Park 5042, Australia. ${ }^{5}$ Department of Public Health, Flinders University, Bedford Park 5042, Australia. ${ }^{6}$ Division of Health Sciences City East Campus, University of South Australia, Adelaide 5001, Australia. ${ }^{7}$ Sansom Institute for Health Research, University of South Australia, Adelaide 5001, Australia.

\section{Acknowledgements}

This study was funded by a Channel 7 Children's Research Foundation Grant. RKG was supported by a National Health and Medical Research Council (NHMRC) Public Health Postdoctoral Fellowship (478115). Support for LB included funds from a FellowshipsSA grant.

\section{Competing interests}

The authors declare that they have no competing interests.

Received: 16 December 2014 Accepted: 10 December 2015 Published online: 13 January 2016

\section{References}

1. Barlow SE, Committee Expert. Expert committee recommendations regarding the prevention, assessment and treatment of child and adolescent overweight and obesity: summary report. Pediatrics. 2007;120(S4):S164-92

2. National Health and Medical Research Council (NHMRC). Clinical practice guidelines for the management of of overweight and obesity in children and adolescents. Canberra: Commonwealth of Australia. 2003.

3. Grzywacz JG, Fuqua J. The social ecology of health: leverage points and linkages. Behav Med. 2000;26:101-14.

4. Swinburn B, Egger G, Fezeela R. Dissecting obesogenic environments: the development and application of a framework for identifying and prioritizing environmental interventions for obesity. Prev Med. 1999;29:563-70.

5. Campbell K, Crawford D. Family food environments as determinants of preschool-aged children's eating behaviours: implications for obesity prevention policy. Aust J Nutr Diet. 2001;58:19-24.

6. Booth SL, Mayer J, Sallis JF, et al. Environmental and societal factors affect food choice and physical activity: rationale, influences and leverage points. Nutr Rev. 2001;59:S21-39.

7. Patrick H, Nicklas TA. A review of family and social determinants of children's eating patterns and diet quality. J Am Coll Nutr. 2005;24:83-92.

8. Ventura AK, Birch LL. Does parenting affect children's eating and weight status? Int J Behav Nutr Phys Act. 2008;17:15. doi:10.1186/1479-5868-5-15.

9. Davison KK, Lawson CT. Do attributes in the physical environment influence children's physical activity? A review of the literature. Int J Behav Nutr Phys Act. 2006;3.

10. Rosenkranz RR, Dzewaltowski DA. Model of the home food environment pertaining to childhood obesity. Nut Rev. 2008;66:123-40.

11. Spurrier NJ, Magarey AA, Golley R, Curnow F, Sawyer MG. Relationships between the home environment and physical activity and dietary patterns of preschool children: a cross-sectional study. Int J Behav Nutr Phys Act. 2008;5(1):31.

12. Oude Luttikhuis $H$, Baur L, Jansen H, Shrewsbury VA, O'Malley C, Stolk RP, Summerbell CD. Interventions for treating obesity in children. Cochrane Database Syst Rev. 2009; CD001872.

13. Summerbell CD, Ashton V, Campbell KJ, Edmunds L, Kelly S, Waters E. Interventions for treating obesity in children. Cochrane Database Syst Rev. 2003; CD001872

14. Wen LM, Baur LA, Rissel CC, et al. Early intervention of multiple home visits to prevent childhood obesity in a disadvantaged population: a home-based randomised controlled trial (Healthy Begginnings Trial). BMC Public Health. 2007;7:76.

15. Donelan-McCall N, Eckenrode J, Olds DL. Home visiting for the prevention of child maltreatment: lessons learned during the past 20 years. Pediatr Clin North Am. 2009;56:389-403.

16. Welsh EJ, Hasan M, Li P. Home-based educational interventions for children with asthma. Cochrane Database Syst Rev. 2011; CD008469.

17. Thyne SM, Fisher-Owens SA. The complexities of home visitation for children with asthma in underserved communities. J Asthma. 2011;48:210.

18. Cole TJ, Bellizzi MC, Flegal KM, Dietz WH. Establishing a standard definition for child overweight and obesity worldwide: international survey. BMJ. 2000;320:1240-3.

19. Cole TJ, Freeman JV, Preece MA. Body mass index reference curves for the UK, 1990. Arch Dis Child. 1995;73:25-9.

20. McCarthy HD, Jarrett KV, Crawley HF. The development of waist circumference percentiles in British children aged 5.0-16.9 years. Eur J Clin Nutr. 2001;55:902-7.

21. Magarey AM, Golley R, Spurrier N, Goodwin E, Ong F. Reliability and validity of the Children's Dietary Questionnaire; a new tool to measure children's dietary patterns. Int J Pediatr Obes. 2009;4:257-65.

22. Smith A, Kellet E, Schmerlaib Y. The Australian guide to healthy eating. Canberra: Commonwealth Department of Health and Family Services; 1998.

23. Burdette HL, Whitaker RC. A national study of neighbourhood safety, outdoor play, television viweing and obesity in preschool children. Pediatrics. 2005;116:657-62.

24. Bronfenbrenner U. Ecological models of human development, 2nd edn. International Encyclopedia of Education, vol. 3. Oxford: Elsevier. 1994. 
25. Davison KK, Birch LL. Childhood overweight: a contextual model and recommendations for future research. Obes Rev. 2001;2:159-71.

26. National Health and Medical Research Council (NHMRC). Dietary guidelines for children and adolescents in australia incorporating infant feeding guidelines for health workers. Canberra: Commonwealth of Australia. 2003.

27. Hill JO, Peters JC. Environmental contributions to the obesity epidemic. Science. 1998;280:1371-4.

28. French SA, Story M, Jeffery RW. Environmental influences on eating and physical activity. Annu Rev Public Health. 2001;22:309-35.
29. Segal L, Sara Opie R, Dalziel K. Theory!: the missing link in understanding the performance of neonate/infant home-visiting programs to prevent child maltreatment: a systematic review. Milbank Q. 2012;90:47-106.

30. Swinburn BA. Obesity prevention: the role of policies, laws and regulations. Aust New Zealand Health Policy. 2008;5:12.

31. Brown JV, Demi AS, Celano MP, et al. A home visitng asthma education program: challenges to program implementation. Health Educ Behav. 2005;32:42-56.
Submit your next manuscript to BioMed Central and we will help you at every step:

- We accept pre-submission inquiries

- Our selector tool helps you to find the most relevant journal

- We provide round the clock customer support

- Convenient online submission

- Thorough peer review

- Inclusion in PubMed and all major indexing services

- Maximum visibility for your research

Submit your manuscript at www.biomedcentral.com/submit
Biomed Central 